\title{
Steam Methane Reforming System for Hydrogen Production: Advanced Exergetic Analysis*
}

\author{
Alicia Boyano $^{1}$, Ana-Maria Blanco-Marigorta ${ }^{2}$, Tatiana Morosuk***3 ${ }^{3}$ George Tsatsaronis ${ }^{4}$ \\ ${ }^{1,3,4}$ Institute for Energy Engineering, Technische Universität Berlin, Germany \\ ${ }^{2}$ Department of Process Engineering, University of Las Palmas de Gran Canaria, Spain \\ E-mails: ${ }^{1}$ a.boyano@ iet.tu-berlin.de, ${ }^{2}$ ablanco@dip.ulpgc.es, \\ ${ }^{3}$ morozyuk@iet.tu-berlin.de, ${ }^{4}$ tsatsaronis@ iet.tu-berlin.de
}

\begin{abstract}
Steam methane reforming (SMR) is one of the most promising processes for the production of hydrogen. Therefore, the overall thermodynamic efficiency of this process is of particular importance. The thermodynamic inefficiencies in a thermal system are related to exergy destruction and exergy loss. However, a conventional exergetic analysis cannot evaluate the mutual interdependencies among the system components nor the real potential for improving the energy conversion system being considered. One of the tools under development for the improvement of energy conversion systems from the thermodynamic viewpoint is the advanced exergetic analysis. In this paper, the avoidable part of the exergy destruction is estimated and the interactions among components of the overall system are evaluated in terms of endogenous and exogenous exergy destruction. The assumptions required for these calculations are discussed in detail, especially for those components that are typically used in chemical processes. Results of this paper suggest options for increasing the thermodynamic efficiency of hydrogen production by steammethane reforming.
\end{abstract}

Keywords: Steam methane reforming (SMR); hydrogen production; conventional exergetic analysis; advanced exergetic analysis.

\section{Introduction}

The continuously increasing demand for energy, and concerns about greenhouse gas emissions have increased the interest in the efficient and cost effective generation and use of hydrogen. Hydrogen is produced industrially mainly through steam reforming of natural gas, coal gasification, water electrolysis, and as a by-product of naphtha reforming. The steam/methane reforming (SMR) process is one of the most widespread ways for producing hydrogen from natural gas (for example, Rosen, 1991; Yang et al., 2009). Therefore, improvements to this process are highly desired.

In a previous authors' study (Boyano et al., 2011), a conventional exergetic analysis of this hydrogen production process was carried out. However, such an analysis cannot evaluate the mutual interdependencies among the system components nor the real potential for improving the energy conversion system being considered.

The purpose of this work is to develop a better understanding of the formation of thermodynamic inefficiencies in an SMR process for hydrogen production (Simpson and Lutz, 2007; Boyano et al., 2011) by means of an advanced exergetic analysis. In this study, the thermodynamically most relevant system components of the total process are identified and information about possibilities for improving the overall thermodynamic efficiency is provided.

\section{SMR process: Modeling and simulation}

The conceptual design of an SMR process shown by Boyano et al. (2011) is used to demonstrate the application of advanced exergetic analysis to an energy-intensive chemical reaction process.

The flow diagram of the SMR system is given in Figure 1a. The hydrogen production process includes two reactants: methane and pure water. This process consists of compressing natural gas from atmospheric pressure to 10 bar to decrease the size of downstream equipment and to take advantage of the increased reaction rates and driving forces seen at higher pressures. The natural gas is then heated. Steam is produced by preheating and vaporizing pure water in several heat exchangers: Shift-reactor heat exchanger (HX-SHIFT), pre-shift heat exchanger (HX-B), and exhaust-gas-stream heat exchanger (HX-A). Steam is needed also to avoid carbon depositions during the endothermic reforming reaction and to be used as a chemical reactant in the water- gas shift reaction. The steam and methane streams are combined and fed to the steam methane reformer. This reactor contains a nickel-based catalyst where the following reactions take place:

$$
\begin{aligned}
& \mathrm{CH}_{4}+\mathrm{H}_{2} \mathrm{O} \rightarrow \mathrm{CO}+3 \mathrm{H}_{2} \\
& \mathrm{CO}+\mathrm{H}_{2} \mathrm{O} \rightarrow \mathrm{CO}_{2}+\mathrm{H}_{2}
\end{aligned}
$$

The reforming reaction (1) is highly endothermic. 


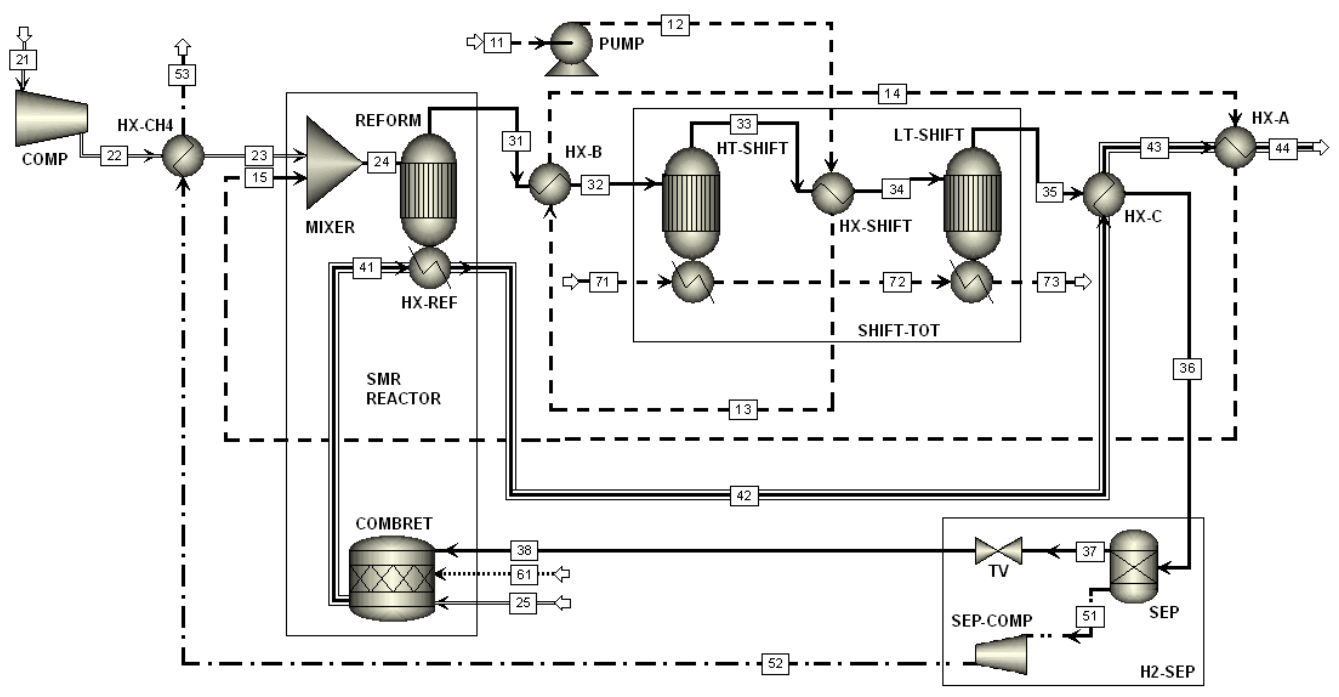

(a)

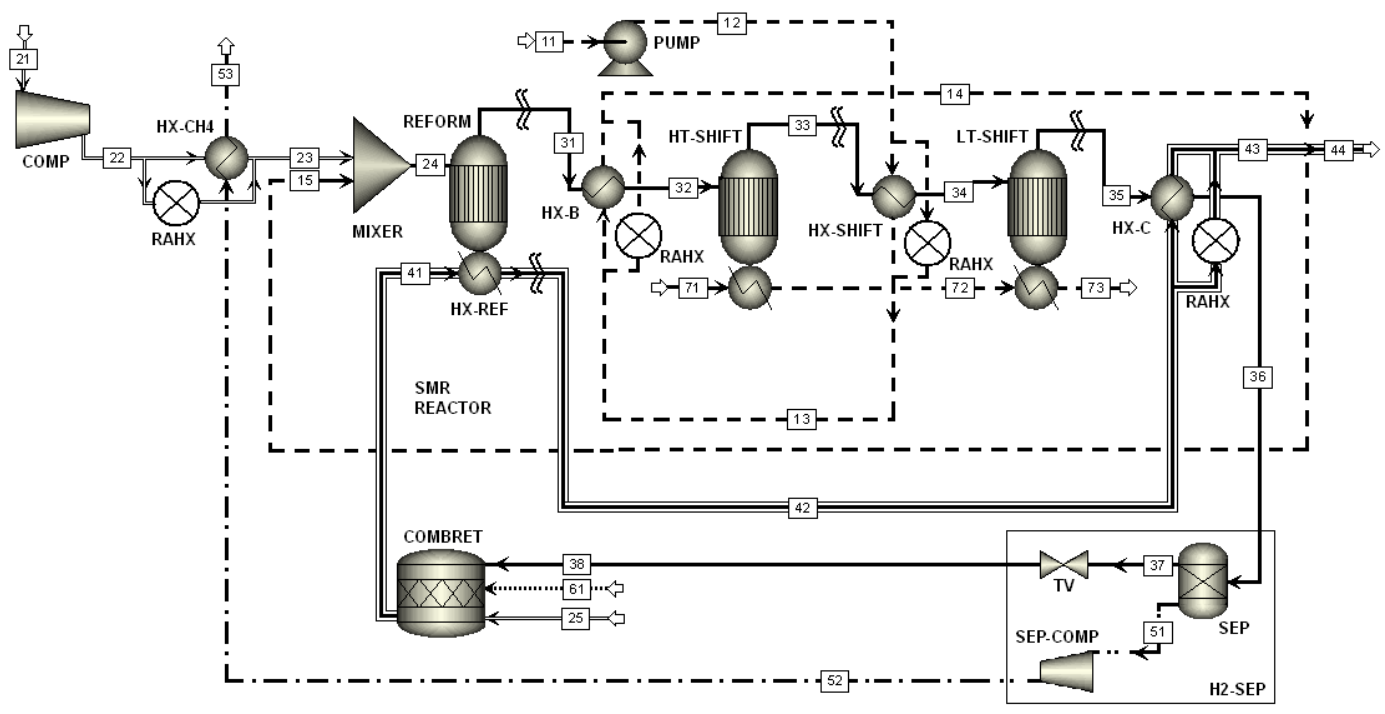

(b)
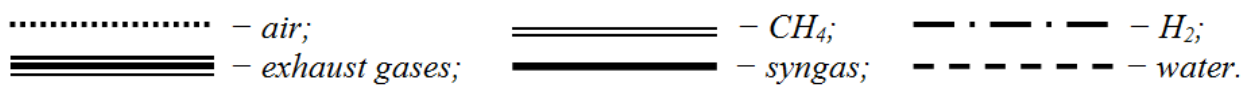

Figure 1. Schematic of a SMR plant for hydrogen production: (a) real plant, and (b) modified flow diagram for conducting the advanced exergetic analysis.

For the analysis, the reformer is modeled using the following components:

- A methane/steam mixer (MIXER) providing stream (stream 24),

- A reformer (REFORM), and

- A combustion chamber (COMBRET) of retentate (stream 38) and methane (stream 25) with air (stream 61) to provide the thermal energy required for the endothermic reforming reaction, and a heat exchanger to transfer the thermal energy from the exhaust gas stream (stream 41) to the reforming reactor (HX-REF).

The heat of reaction is supplied by the exhaust gases provided by the combustion of (a) additional methane, and (b) the retentate stream, i.e. the stream resulted after hydrogen separation. The resulting synthesis gas is cooled through a heat exchanger to enter first the high temperature reactor (HT-SHIFT) and then the lower temperature reactor (LT-SHIFT). In both reactors, the reaction occurs over a promoted nickel catalyst to increase the amount of $\mathrm{H}_{2}$ while decreasing the $\mathrm{CO}$ (Equation 2). The next step is to heat up the gas stream before the hydrogen enters the separation unit. The hydrogen separation unit is modeled as a metallic membrane able to separate the hydrogen with a high efficiency and a purity of $100 \%$ (Simpson and Lutz, 2007; Boyano et al., 2011).

The analysis presented in this paper uses the main system component models: A chemical equilibrium model for the chemical reactors and a detailed heat integration to perform exergy analysis. Heat integration is an essential part of this study because in optimal performance of an SMR system depends largely on the amount of methane required by the system. The following parameters are assumed for the analysis (Boyano et al., 2011): 
- The input rate of methane entering the reforming reactor was set to $1 \mathrm{kmol} / \mathrm{s}$ of $\mathrm{CH}_{4}$, to produce $2.67 \mathrm{kmol} / \mathrm{s}$ of $\mathrm{H}_{2}$.

- Air composition: $\mathrm{O}_{2}-21 \mathrm{~mol} \%, \mathrm{~N}_{2}-79 \mathrm{~mol} \%$.

- Water gas shift reactors: $T_{33}=350^{\circ} \mathrm{C} ; p_{33}=10.13$ bar, and $T_{35}=200^{\circ} \mathrm{C} ; p_{35}=10.13 \mathrm{bar}$.

- $\mathrm{H}_{2}$ separator: The separation efficiency amounts to $90 \%$, the purity of $\mathrm{H}_{2}$ is $99 \%$.

- Reformer: $T_{31}=700^{\circ} \mathrm{C} ; \quad p_{31}=10.13$ bar. The steam/methane molar ratio is equal to 3.6 (Simpson and Lutz, 2007) so that no carbon deposition takes place.

- Other parameters for equipment: $\eta_{\text {COMP }}=70 \% ; \eta_{\text {PUMP }}$ $=85 \%$; the chemical conversion of the fuel in the COMBRET is equal to $97 \%$. The effectiveness of heat exchangers is equal to $90 \%$ and it is assumed that there are no pressure losses across the heat exchangers.

The ASPEN plus software (Aspen Plus, 2007) was used to model the SMR system (the mass flow rate, temperature, pressure and chemical composition of all streams). The designs of the main components as well as the engineering design parameters are based on data published in (Twigg, 1989). Methane was used to simulate natural gas feedstock.

All exergy values are calculated using the reference environment $T_{0}=298.15 \mathrm{~K}, p_{0}=1.013$, and Ahrendts' model (Model I in Bejan et al., 1996) for calculating standard molar chemical exergy values.

Table 1 shows the main results of simulation including the values of the chemical and physical exergies.

The following work and heat rates apply to the components of the SMR plant: $\dot{W}_{\text {COMP }}=8.703 \mathrm{MW}$, $\dot{W}_{P U M P}=0.058 \mathrm{MW} ; \quad \dot{W}_{H 2-S E P}=4.790 \mathrm{MW} ; \quad \dot{Q}_{H X-A}$ $=91.902 \mathrm{MW} ; \dot{Q}_{H X-B}=72.413 \mathrm{MW} ; \dot{Q}_{H X-C}=50.712 \mathrm{MW}$; $\dot{Q}_{H X-C H 4}=8.469 \mathrm{MW} ; \dot{Q}_{H X-S H I F T}=30.113 \mathrm{MW} ; \dot{Q}_{R E F}=$ $199.267 \mathrm{MW} ; \dot{Q}_{H T-S H I F T}=1.378 \mathrm{MW} ; \dot{Q}_{L T-S H I F T}=$ 9.530; and $\dot{Q}_{C O M B R E T}=695.569 \mathrm{MW}$ (the energy loss is equal to $12.589 \mathrm{MW}$ ).

Table 1. Thermodynamic data of streams for the SMR plant.

\begin{tabular}{|c|c|c|c|c|c|c|c|}
\hline Stream, $j$ & Material stream & $\dot{m}_{j}(\mathrm{~kg} / \mathrm{s})$ & $T_{j}\left({ }^{\circ} \mathrm{C}\right)$ & $p_{j}($ bar $)$ & $\dot{E}_{j}^{C H}(\mathrm{MW})$ & $\dot{E}_{j}^{P H}(\mathrm{MW})$ & $\dot{E}_{j}(\mathrm{MW})$ \\
\hline 11 & Water & 57.649 & 25 & 1.013 & 0.04 & 0.14 & 0.18 \\
\hline 12 & Water & 57.649 & 25 & 10.13 & 0.09 & 0.14 & 0.23 \\
\hline 13 & Water & 57.649 & 149 & 10.13 & 5.89 & 0.14 & 6.03 \\
\hline 14 & Water *) & 57.649 & 180 & 10.13 & 32.08 & 0.14 & 32.22 \\
\hline 15 & Water & 57.649 & 500 & 10.13 & 71.69 & 0.14 & 71.83 \\
\hline 21 & $\mathrm{CH}_{4}$ & 16.043 & 25 & 1.013 & 0.01 & 824.40 & 824.41 \\
\hline 22 & $\mathrm{CH}_{4}$ & 16.043 & 238 & 10.13 & 7.95 & 824.40 & 832.35 \\
\hline 23 & $\mathrm{CH}_{4}$ & 16.043 & 400 & 10.13 & 12.49 & 824.40 & 836.89 \\
\hline 25 & $\mathrm{CH}_{4}$ & 1.925 & 25 & 10.13 & 0.00 & 98.92 & 98.92 \\
\hline 31 & Syngas & 73.691 & 700 & 10.13 & 105.80 & 921.00 & 1026.80 \\
\hline 32 & Syngas & 73.691 & 350 & 10.13 & 61.08 & 921.00 & 982.08 \\
\hline 33 & Syngas & 73.691 & 350 & 10.13 & 60.89 & 920.30 & 981.19 \\
\hline 34 & Syngas & 73.691 & 200 & 10.13 & 47.76 & 920.30 & 968.06 \\
\hline 35 & Syngas & 73.691 & 200 & 10.13 & 46.18 & 916.00 & 962.18 \\
\hline 36 & Syngas & 73.691 & 450 & 10.13 & 70.65 & 916.00 & 986.65 \\
\hline 38 & Syngas & 68.351 & 447 & 1.013 & 28.76 & 296.60 & 325.36 \\
\hline 41 & Exhaust gases & 220.298 & 1341 & 1.013 & 270.20 & 21.27 & 291.47 \\
\hline 42 & Exhaust gases & 220.298 & 749 & 1.013 & 116.50 & 21.27 & 137.77 \\
\hline 43 & Exhaust gases & 220.298 & 587 & 1.013 & 81.80 & 21.27 & 103.97 \\
\hline 44 & Exhaust gases & 220.298 & 272 & 1.013 & 29.44 & 21.27 & 50.71 \\
\hline 52 & $\mathrm{H}_{2}$ & 5.340 & 450 & 1.013 & 12.54 & 623.30 & 635.84 \\
\hline 53 & $\mathrm{H}_{2}$ & 5.340 & 342 & 1.013 & 7.88 & 623.30 & 631.18 \\
\hline 61 & Air & 150.022 & 25 & 1.013 & 0.00 & 0.89 & 0.89 \\
\hline 71 & Water & 4.200 & 25 & 1.013 & 0.00 & - & 0.00 \\
\hline 72 & Water & 4.200 & 102 & 1.013 & 0.20 & - & 0.20 \\
\hline 73 & Water & 4.200 & 113 & 1.013 & 2.37 & - & 2.37 \\
\hline
\end{tabular}

") Vapor fraction is equal to $0.555 \mathrm{~kg} / \mathrm{kg}$.

\section{Conventional exergetic analysis}

An exergetic analysis is the best approach for evaluating energy conversion systems from the thermodynamic viewpoint (Bejan et al., 1996; Tsatsaronis and Cziesla, 2002). The exergy analysis provides a powerful tool for assessing the quality and quantity of a resource. An exergy analysis identifies the location, magnitude and sources of thermodynamic inefficiencies in an energy conversion system. In a conventional exergetic evaluation, the following variables are used (Tsatsaronis and Cziesla, 2002): (a) exergy destruction rate within the $k^{\text {th }}$ plant component $\dot{E}_{D, k}=\dot{E}_{F, k}-\dot{E}_{P, k}$ (exergy balance for the $k^{\text {th }}$ component); (b) exergetic efficiency of the $k^{\text {th }}$ plant component $\varepsilon_{k}=\frac{\dot{E}_{P, k}}{\dot{E}_{F, k}} ;$ and of the overall system $\varepsilon_{\text {tot }}=\frac{\dot{E}_{P, t o t}}{\dot{E}_{F, t o t}} ;$ and (c) exergy destruction ratio for the $k^{\text {th }}$ plant component $y_{k}=\frac{\dot{E}_{D, k}}{\dot{E}_{F, t o t}}$.

For defining the exergetic efficiency of some components, some explanations might be necessary: For the reformer, the desired product is the addition of chemical (mainly) and thermal exergy to the mixture of $\mathrm{CH}_{4} / \mathrm{H}_{2} \mathrm{O} / \mathrm{CO} / \mathrm{H}_{2}$. This addition occurs at the expense of thermal exergy provided in the HX-REF by the combustion products. In the shift reactors the desired product is (a) the 
addition of hydrogen (mainly) to the mixture of $\mathrm{CO} / \mathrm{H}_{2} / \mathrm{CO}_{2} / \mathrm{H}_{2} \mathrm{O} / \mathrm{CH}_{4}$ and, (b) the addition of thermal exergy to the stream $71 \rightarrow 73$. This occurs at the expense of (a) the composition change for the remaining chemical components of the mixture, and (b) the thermal exergy of the mixture. All these definitions are consistent with the SPECO principle (Lazzaretto and Tsatsaronis, 2006). Thus, the following definitions of exergy of fuel and exergy of product for SMR plant components were used (Bejan et al., 1996; Tsatsaronis and Cziesla, 2002; Lazzaretto and Tsatsaronis, 2006):

- Pump: $\dot{E}_{F, P U M P}=\dot{W}_{P U M P}$ and $\dot{E}_{P, P U M P}=\dot{E}_{12}-\dot{E}_{11}$

- Compressor: $\dot{E}_{F, C O M P}=\dot{W}_{C O M P}$ and $\dot{E}_{P, C O M P}=\dot{E}_{22}-\dot{E}_{21}$

- Heat exchangers: $\dot{E}_{F, H X}=\dot{E}_{h o t, i n}-\dot{E}_{\text {hot,out }}$ and $\dot{E}_{P, H X}=\dot{E}_{\text {cold,out }}-\dot{E}_{\text {cold,in }}$

- Reformer: $\dot{E}_{F, R E F O R M}=\dot{E}_{41}-\dot{E}_{42}$ and $\dot{E}_{P, R E F O R M}=\dot{E}_{31}-\left(\dot{E}_{23}+\dot{E}_{15}\right)$

- Combustion chamber:

$\dot{E}_{F, C O M B R E T}=\dot{E}_{25}+\dot{E}_{38}$ and $\dot{E}_{P, C O M B R E T}=\dot{E}_{41}-\dot{E}_{61}$

- Hydrogen separator:

$\dot{E}_{F, H 2-S E P}=\dot{W}_{H 2-S E P}+\dot{m}_{38}\left(e_{36}^{P H}-e_{38}^{P H}\right)$ and $\dot{E}_{P, H 2-S E P}=\dot{E}_{52}^{C H}+\dot{E}_{38}^{C H}-\dot{E}_{36}^{C H}+\dot{m}_{52}\left(e_{52}^{P H}-e_{36}^{P H}\right)$

- Water-gas-shift reactors:

$$
\begin{aligned}
\dot{E}_{F, S H I F T}= & {\left[\left(\dot{m}_{\text {in }}^{\mathrm{CO}} e_{\text {in }}^{\mathrm{CO}}-\dot{m}_{\text {out }}^{\mathrm{CO}} e_{\text {out }}^{\mathrm{CO}}\right)\right.} \\
& +\left(\dot{m}_{\text {in }}^{\mathrm{H} 2 \mathrm{O}} e_{\text {in }}^{\mathrm{H} 2 \mathrm{O}}-\dot{m}_{\text {out }}^{\mathrm{H} 2 \mathrm{O}} e_{\text {out }}^{\mathrm{H} 2 \mathrm{O}}\right) \\
& +\left(\dot{m}_{\text {in }}^{\mathrm{CH} 4} e_{\text {in }}^{\mathrm{CH} 4}-\dot{m}_{\text {out }}^{\mathrm{CH} 4} e_{\text {out }}^{\mathrm{CH} 4}\right) \\
& \left.+\left(\dot{m}_{\text {out }}^{\mathrm{CO} 2} e_{\text {out }}^{\mathrm{CO} 2}-\dot{m}_{\text {in }}^{\mathrm{CO} 2} e_{\text {in }}^{\mathrm{CO} 2}\right)\right]^{\mathrm{CH}}
\end{aligned}
$$

and $\dot{E}_{P, S H I F T-T O T}=\left(\dot{m}_{\text {in }}^{H 2} e_{\text {in }}^{C H, H 2}-\dot{m}_{\text {out }}^{H 2} e_{\text {out }}^{C H, H 2}\right)$

$$
+\left(\dot{E}_{\text {water,out }}-\dot{E}_{\text {water }, \text { in }}\right)
$$

The exergetic balance for the overall plant is $\dot{E}_{F, t o t}=\dot{E}_{P, t o t}+\sum_{k} \dot{E}_{D, k}+\dot{E}_{L, t o t}$. The exergy losses of the overall SMR plant are equal to the sum of exergy of exhaust gases and exergy difference between outlet and inlet streams of the cooling water of the SHIFT-TOT, $\dot{E}_{L, t o t}=\dot{E}_{44}+\left(\dot{E}_{73}-\dot{E}_{71}\right)$

The exergetic efficiency of the overall SMR system is

$$
\begin{aligned}
\varepsilon & =\frac{\dot{E}_{P, t o t}}{\dot{E}_{F, t o t}} \\
& =\frac{\dot{E}_{53}}{\left(\dot{E}_{11}+\dot{E}_{21}+\dot{E}_{61}+\dot{E}_{25}+\dot{W}_{C O M P}+\dot{W}_{P U M P}+\dot{W}_{H 2-S E P}\right)}
\end{aligned}
$$

The exergetic efficiency of the overall SMR plant is $67 \%$. The data obtained from the conventional exergetic analysis of the SMR system (Table 2) show that the combustion chamber has the highest exergy destruction value followed by the hydrogen separation unit, the reformer and some heat exchangers. The exergy destruction is mainly due to the chemical reaction that takes place in the combustion chamber.

Table 2. Results obtained from the conventional exergetic analysis of the SMR plant ( $\left.\dot{E}_{L, t o t}=53.08 \mathrm{MW}\right)$.

\begin{tabular}{lrrrrc}
\hline Component & \multicolumn{1}{c}{$\dot{E}_{F, k}$} & \multicolumn{1}{c}{$\dot{E}_{P, k}$} & \multicolumn{1}{c}{$\dot{E}_{D, k}$} & \multicolumn{1}{c}{$\begin{array}{c}y_{k} \\
(\mathrm{MW})\end{array}$} & \multicolumn{1}{c}{$\begin{array}{c}\varepsilon_{k} \\
(\mathrm{MW})\end{array}$} \\
\hline COMBRET & 424.30 & 290.60 & 133.70 & 14.25 & 68.49 \\
H2-SEP & 41.56 & 11.42 & 30.14 & 3.21 & 27.48 \\
REFORM & 153.80 & 118.10 & 35.70 & 3.81 & 76.78 \\
HT-SHIFT & 9.39 & 8.67 & 0.72 & 0.08 & 92.33 \\
HX-SHIFT & 13.12 & 5.80 & 7.32 & 0.78 & 44.20 \\
LT-SHIFT & 63.43 & 59.69 & 3.73 & 0.40 & 94.11 \\
HX-A & 52.35 & 39.61 & 12.74 & 1.36 & 75.66 \\
HX-B & 44.69 & 26.19 & 18.50 & 1.97 & 58.60 \\
HX-C & 34.68 & 24.47 & 10.21 & 1.09 & 70.55 \\
HX-CH4 & 4.66 & 4.54 & 0.12 & 0.01 & 97.43 \\
COMP & 8.70 & 7.95 & 0.75 & 0.08 & 91.31 \\
PUMP & 0.06 & 0.05 & 0.01 & $<0.01$ & 90.78 \\
Overall & $\mathbf{9 3 7 . 9 0}$ & $\mathbf{6 3 1 . 2 0}$ & $\mathbf{2 5 3 . 6 0}$ & $\mathbf{2 7 . 0 4}$ & $\mathbf{6 7 . 3 0}$ \\
system & & & & & \\
\hline
\end{tabular}

\section{Advanced exergetic analysis}

A conventional exergetic analysis does not provide any information with respect to (a) the potential for improving the overall system and the single components, and (b) the interactions among the components. To answer these questions, the advanced exergetic analysis was developed.

\subsection{Unavoidable and avoidable thermodynamic inefficiencies}

The real thermodynamic inefficiencies in an energy conversion system are related to exergy destruction and exergy loss. Exergy destruction is caused by effects such as chemical reactions, heat transfer through a finite temperature difference, mixing of matter of different compositions or states, unrestrained expansion, and friction. At any given state of technological development, some exergy destruction within a system component will always be unavoidable due to physical and economical constraints (Tsatsaronis and Park, 2002; Cziesla et al., 2006; Tsatsaronis and Morosuk, 2008a and 2008b). For this reason, the development of an advanced exergetic analysis for evaluating the chemical process, where the unavoidable and avoidable parts of the exergy destruction are calculated, can be of value for improving the overall system performance because it allows engineers to focus only on the avoidable inefficiencies.

The general methodology for splitting the exergy destruction into unavoidable/avoidable parts ( $\dot{E}_{D, k}=\dot{E}_{D, k}^{U N}+\dot{E}_{D, k}^{A V}$ ) is presented in (Tsatsaronis and Park, 2002; Cziesla et al., 2006; Tsatsaronis and Morosuk, 2008a and 2008b). In order to calculate the value of the unavoidable exergy destruction within the $k^{\text {th }}$ component 


$$
\dot{E}_{D, k}^{U N}=\dot{E}_{P, k}^{r e a l}\left(\frac{\dot{E}_{D}}{\dot{E}_{P}}\right)_{k}^{U N}
$$

the following procedure should be used to estimate the term $\left(\frac{\dot{E}_{D}}{\dot{E}_{P}}\right)_{k}^{U N}$; i.e. the ratio between the exergy destruction and the exergy of the product for the $k^{\text {th }}$ component at unavoidable conditions:

- Each component is simulated in isolation from the overall system,

- The flows entering the component being considered have the same thermodynamic parameters as in the real case,

- Mass, energy and exergy balances should be fulfilled, and

- The operating conditions correspond to irreversibilities within the component that just cannot be further reduced in the foreseeable future.

Table 3 shows the parameters used for calculating the unavoidable exergy destruction within components of the SMR system.

An approach for estimating the unavoidable part of the exergy destruction associated with the steam-methane reforming reactor (i.e. REFORM and COMBRET) of the SMR system is discussed by Boyano at al. (2012).

For all heat exchangers we assumed that the value of the product exergy at unavoidable operating conditions remains the same as for the real operating conditions, i.e. $\dot{E}_{P, H X}=\dot{E}_{\text {cold,out }}-\dot{E}_{\text {cold,in }}=$ const . Therefore, the heat rate within each heat exchanger also remains the same as for the real operating conditions, i.e. $\dot{Q}_{H X}=\dot{m}_{\text {cold }}\left(h_{\text {cold,out }}-h_{\text {cold,in }}\right)=$ const .

For the compressor and pump, the unavoidable operating conditions are defined using a high value for $\eta_{s}^{U N}$ (Table 3) as well as $\dot{m}_{21}=$ const and $\dot{m}_{11}=$ const .

The unavoidable operating conditions for both SHIFT reactors correspond to the lower temperature of the SHIFT reaction (Table 3), and for the hydrogen separator - to the higher separation efficiency of hydrogen (99\%) compared with the base case $(90 \%)$.

The values of $\left(\frac{\dot{E}_{D, k}}{\dot{E}_{P, k}}\right)^{U N}$ are given in Table 3 as well as the values of $\dot{E}_{D, k}^{U N}$ and $\dot{E}_{D, k}^{A V}$ are given in Table 4.

After calculating the unavoidable exergy destruction (Eq.(4)), the avoidable part of exergy destruction within the $k^{\text {th }}$ component is obtained from

$\dot{E}_{D, k}^{A V}=\dot{E}_{D, k}-\dot{E}_{D, k}^{U N}$

\subsection{Endogenous and exogenous thermodynamic inefficiencies}

The interactions among different components of the same system can be estimated and the quality of the conclusions obtained from an exergetic analysis can be improved, when the exergy destruction in each (important) system component is split into endogenous/exogenous parts. The methodology for splitting the exergy destruction into endogenous/exogenous parts for the components of different energy-conversion systems can be found in Tsatsaronis and Morosuk (2008a; 2008b; 2010) and Morosuk and Tsatsaronis (2009).

In general, for splitting the exergy destruction into endogenous and exogenous parts, we need to define the socalled theoretical operation conditions (superscript $T$ ) for each component. Using the theoretical operating conditions, we can achieve:

- For pumps and compressors, $\dot{E}_{D, k}^{T}=0$ with $\eta_{s}=1$;

- For heat exchangers, the only possible condition is $\dot{E}_{D, k}^{T}=\min$, with $\Delta T_{\min }^{T}=0$;

- For components where a chemical reaction occurs (HTSHIFT, LT-SHIFT, REFORM and COMBRET), the condition $\dot{E}_{D, k}^{T}=0 \quad\left(\varepsilon_{k}^{T}=1\right)$ can be achieved only through fulfilling the exergy balance for the component ( $\dot{E}_{F, k}^{T}=\dot{E}_{P, k}^{T}$ ), and by ignoring the mass and the energy balances. A detailed explanation of this methodology is given by Morosuk and Tsatsaronis (2009).

The so-called hybrid processes (only one component is real, i.e. operates with its real efficiency, while all other components operate in a theoretical way) are employed to split the exergy destruction into endogenous and exogenous parts. In a hybrid process, the exergy destruction within the component being considered represents the endogenous exergy destruction for this component. The step-by-step introduction of irreversibilities in each system component enables us to calculate the endogenous exergy destruction within each component (Tsatsaronis and Morosuk, 2008a; 2008b; 2010; Morosuk and Tsatsaronis, 2009).

Note that for the simulation of the overall system at the theoretical and hybrid conditions, the exergy of the product of the overall system should always remain unchanged and equal to the value in the real case $\left(\dot{E}_{P, t o t}=\right.$ const $)$. Only in this way we can estimate the endogenous exergy destruction within the $k^{\text {th }}$ component by considering the effects of (1) irreversibility, and (2) mass flow rates of the working fluids.

The thermodynamic data for the theoretical and the hybrid operating conditions are given in Table 3 . Note that

- $\dot{E}_{P, t o t}=\dot{E}_{53}=$ const , therefore $\dot{m}_{53}=$ const,

- the chemical composition of the syngas (streams 31 through 38) and exhaust gases (streams 41 through 44), and also the chemical conversion for the theoretical and the hybrid conditions of HT-SHIFT, LT-SHIFT, REFORM and COMBRET remain the same as for the real operation conditions,

- the assumption $\varepsilon_{k}^{H}=\varepsilon_{k}^{R}$ is used for the hybrid conditions for the HT-SHIFT, LT-SHIFT, REFORM and COMBRET,

- the HX-A does not exist for the theoretical and, therefore, hybrid conditions, because $T_{14}^{T}>T_{43}^{T}$. For the reformer, $T_{14}^{T}=T_{15}^{T}$ and $T_{14}^{H}=T_{15}^{H}$.

The SMR system at theoretical and hybrid conditions can be simulated only if the following two concepts (changes) are applied:

(a) "Cutting" the schematic into sub-systems for which energy and mass balances are fulfilled. This "cutting" is required immediately after each chemical reactor: 
HT-SHIFT, LT-SHIFT, REFORM and COMBRET

(Morosuk and Tsatsaronis, 2009), and

(b) Introducing the reversible adiabatic heat exchangers

(RAHX) in parallel with all heat exchangers

(Tsatsaronis and Morosuk, 2010).

The modified schematic of the SMR plant used to simulate theoretical and hybrid conditions is given in Figure 1b. Finally, the values of $\dot{E}_{D, k}^{E N}$ and $\dot{E}_{D, k}^{E X}$ are given in Table 4.
By combining the two concepts of splitting the exergy destruction, we obtain

- the unavoidable endogenous part of the exergy destruction $\left(\dot{E}_{D, k}^{U N, E N}\right)$, which cannot be reduced because of technical limitations for the $k^{\text {th }}$ component,

$$
\dot{E}_{D, k}^{U N, E N}=\dot{E}_{P, k}^{E N}\left(\frac{\dot{E}_{D, k}}{\dot{E}_{P, k}}\right)^{U N}
$$

Table 3. Key design parameters.

\begin{tabular}{|c|c|c|c|c|c|c|c|}
\hline \multirow{3}{*}{ Component } & \multirow{3}{*}{$\begin{array}{l}\text { Design } \\
\text { parameter } \\
\quad \text { (unit) }\end{array}$} & \multirow{3}{*}{$\begin{array}{l}\text { Design- } \\
\text { point }\end{array}$} & \multicolumn{2}{|c|}{$\begin{array}{c}\text { Variables used to calculate } \\
\text { the unavoidable exergy } \\
\text { destruction }\end{array}$} & \multicolumn{3}{|c|}{$\begin{array}{l}\text { Variables used to calculate } \\
\text { the endogenous exergy destruction }\end{array}$} \\
\hline & & & \multirow[b]{2}{*}{$\begin{array}{l}\text { Design } \\
\text { parameter }\end{array}$} & \multirow{2}{*}{$\left(\frac{\dot{E}_{D}}{\dot{E}_{P}}\right)_{k}^{U N}$} & \multicolumn{2}{|c|}{ Design parameter } & \multirow{2}{*}{$\begin{array}{c}\dot{E}_{P, k}^{E N} \\
(\mathrm{MW})\end{array}$} \\
\hline & & & & & $\begin{array}{l}\text { Theoretical } \\
\text { conditions }\end{array}$ & $\begin{array}{c}\text { Hybrid } \\
\text { conditions }\end{array}$ & \\
\hline COMP & $\eta_{s}(-)$ & 0.85 & 0.93 & 0.0445 & 1.0 & 0.85 & 6.412 \\
\hline PUMP & $\eta_{s}(-)$ & 0.85 & 0.93 & 0.0755 & 1.0 & 0.85 & 0.041 \\
\hline HX-A & $\Delta T(\mathrm{~K})$ & $\left.25^{*}\right)$ & $\left.15^{*}\right)$ & 0.0412 & \multicolumn{3}{|c|}{$\begin{array}{l}\text { The HX-A does not exist for the theoretical and, } \\
\text { therefore, hybrid operation conditions, because } \\
\qquad T_{14}^{T}>T_{43}^{T}\end{array}$} \\
\hline HX-B & $\Delta T(\mathrm{~K})$ & $\left.25^{*}\right)$ & $\left.15^{*}\right)$ & 0.0626 & $T_{14}^{T}=T_{31}^{R}$ & $T_{14}^{H}=T_{15}^{H}=T_{15}^{R}$ & 30.761 \\
\hline $\mathrm{HX}-\mathrm{C}$ & $\Delta T(\mathrm{~K})$ & $\left.25^{*}\right)$ & $15^{*)}$ & 0.0145 & $T_{36}^{T}=T_{42}^{T}$ & $T_{36}^{H}=T_{36}^{R}$ & 19.495 \\
\hline $\mathrm{HX}-\mathrm{CH} 4$ & $\Delta T(\mathrm{~K})$ & $\left.25^{*}\right)$ & $15^{*)}$ & 0.0218 & $T_{23}^{T}=T_{52}^{T}$ & $T_{23}^{H}=T_{15}^{H}$ & 18.083 \\
\hline \multirow[t]{3}{*}{ HT-SHIFT $^{* * *}$} & $T\left({ }^{\circ} \mathrm{C}\right)$ & 350 & 300 & 0.0807 & $T_{32}^{T}=T_{32}^{R}$ & $T_{32}^{H}=T_{32}^{R}$ & 8.600 \\
\hline & & & & & $T_{33}^{T}=T_{33}^{R}$ & $T_{33}^{H}=T_{33}^{R}$ & \\
\hline & $\chi(\operatorname{mol} \%)$ & & & & $\chi_{33}^{T}=\chi_{33}^{R}$ & $\chi_{33}^{H}=\chi_{33}^{R}$ & \\
\hline HX-SHIFT & $\Delta T(\mathrm{~K})$ & $\left.25^{*}\right)$ & $15^{*)}$ & 0.2057 & $T_{13}^{T}=T_{34}^{T}$ & $T_{13}^{H}=T_{13}^{R}$ & 7.063 \\
\hline \multirow[t]{3}{*}{ LT-SHIFT $^{* * *}$} & $T\left({ }^{\circ} \mathrm{C}\right)$ & 200 & 150 & 0.0620 & $T_{34}^{T}=T_{34}^{R}$ & $T_{34}^{H}=T_{34}^{R}$ & 58.131 \\
\hline & & & & & $T_{35}^{T}=T_{35}^{R}$ & $T_{35}^{H}=T_{35}^{R}$ & \\
\hline & $\chi(\mathrm{mol} \%)$ & & & & $\chi_{35}^{T}=\chi_{35}^{R}$ & $\chi_{35}^{H}=\chi_{35}^{R}$ & \\
\hline \multirow[t]{5}{*}{ REFORM $^{* * *}$} & Mixer & $\begin{array}{l}\text { Base } \\
\text { case }\end{array}$ & $\begin{array}{c}\text { Isothermal } \\
\text { Isobaric } \\
\end{array}$ & \multirow[t]{5}{*}{0.2703} & $T_{31}^{T}=T_{31}^{R}$ & $T_{31}^{T}=T_{31}^{R}$ & 100.170 \\
\hline & $T_{41}\left({ }^{\circ} \mathrm{C}\right)$ & 1340 & 1340 & & $T_{23}^{T}=T_{15}^{T}$ & $T_{41}^{T}=T_{41}^{R}$ & \\
\hline & $T_{31}\left({ }^{\circ} \mathrm{C}\right)$ & 700 & 800 & & $T_{41}^{T}=T_{41}^{R}$ & $\chi_{31}^{H}=\chi_{31}^{R}$ & \\
\hline & $S / M(-)$ & 3.6 & 3.6 & & $T_{42}^{T}=T_{31}^{T}$ & & \\
\hline & $\begin{array}{l}\mathrm{CH}_{4} \\
\text { conversion }\end{array}$ & 0.8323 & 0.9073 & & $\chi_{31}^{T}=\chi_{31}^{R}$ & & \\
\hline \multirow[t]{2}{*}{ H2-SEP } & $\begin{array}{l}\mathrm{H}_{2} \\
\text { Separation } \\
\text { efficiency } \\
(\%)\end{array}$ & 90 & 99 & \multirow[t]{2}{*}{0.5847} & \multirow[t]{2}{*}{100} & \multirow[t]{2}{*}{$\begin{array}{c}90 \\
\chi_{52}^{H}=\chi_{52}^{R} \\
4.79\end{array}$} & 15.688 \\
\hline & $\begin{array}{l}\dot{W}_{H 2-S E P} \\
(\mathrm{MW})\end{array}$ & 4.79 & 6.00 & & & & \\
\hline \multirow[t]{3}{*}{ COMBRET $^{* * *)}$} & $\begin{array}{l}\text { Excess air } \\
(\%)\end{array}$ & 20 & 5 & \multirow[t]{3}{*}{0.3420} & \multirow{3}{*}{$\begin{array}{c}\frac{\dot{m}_{\text {air }}}{\dot{m}_{f u e l}}=\text { real } \\
\dot{m}_{25}^{T}=0 \\
\chi_{41}^{T}=\chi_{41}^{R}\end{array}$} & $\frac{\dot{m}_{\text {air }}}{\dot{m}}=$ real & 242.907 \\
\hline & $T_{41}\left({ }^{\circ} \mathrm{C}\right)$ & 1341 & 1460 & & & $\dot{m}_{f u e l}$ & \\
\hline & $\begin{array}{l}\text { Heat duty } \\
\text { (MW) }\end{array}$ & 12.5 & 0 & & & $\begin{array}{c}\dot{m}_{25}^{T}=0 \\
\chi_{41}^{H}=\chi_{41}^{R}\end{array}$ & \\
\hline
\end{tabular}

\footnotetext{
*) $\Delta T$ refers to the average thermodynamic temperature within a heat exchanger.

${ }^{* * *}$ The assumption $\varepsilon_{k}^{H}=\varepsilon_{k}^{R}$ is used for the hybrid operation conditions for the HT-SHIFT, LT-SHIFT, REFORM and COMBRET.
} 
Table 4. Results obtained from the conventional and advanced exergetic analyses of the SMR plant.

\begin{tabular}{|c|c|c|c|c|c|c|c|c|}
\hline \multirow{2}{*}{ Component } & \multirow{2}{*}{$\begin{array}{c}\dot{E}_{D, k}^{E N} \\
(\mathrm{MW})\end{array}$} & \multirow{2}{*}{$\begin{array}{c}\dot{E}_{D, k}^{E X} \\
(\mathrm{MW})\end{array}$} & \multirow{2}{*}{$\begin{array}{c}\dot{E}_{D, k}^{U N} \\
\text { (MW) }\end{array}$} & \multirow{2}{*}{$\begin{array}{c}\dot{E}_{D, k}^{A V} \\
(\mathrm{MW})\end{array}$} & \multicolumn{2}{|c|}{$\dot{E}_{D, k}^{U N}(\mathrm{MW})$} & \multicolumn{2}{|c|}{$\dot{E}_{D, k}^{A V}(\mathrm{MW})$} \\
\hline & & & & & $\dot{E}_{D, k}^{U N, E N}$ & $\dot{E}_{D, k}^{U N, E X}$ & $\dot{E}_{D, k}^{A V, E N}$ & $\dot{E}_{D, k}^{A V, E X}$ \\
\hline COMBRET & 111.75 & 21.95 & 99.38 & 34.32 & 83.07 & 16.31 & 28.68 & 5.64 \\
\hline H2-SEP & - & - & 6.68 & 23.46 & - & - & - & - \\
\hline REFORM & 30.31 & 5.39 & 31.92 & 3.78 & 27.08 & 4.84 & 3.23 & 0.55 \\
\hline HT-SHIFT & 0.72 & 0 & 0.70 & 0.02 & 0.69 & 0.0 .03 & 0.03 & 0 \\
\hline HX-SHIFT & 3.13 & 4.19 & 1.19 & 6.13 & 1.45 & -0.26 & 1.68 & 4.45 \\
\hline LT-SHIFT & 3.64 & 0.09 & 3.70 & 0.03 & 3.61 & 0.09 & 0.03 & 0 \\
\hline $\mathrm{HX}-\mathrm{A}$ & - & - & 1.63 & 11.11 & - & - & - & - \\
\hline HX-B & 13.25 & 5.25 & 1.64 & 16.86 & 1.93 & -0.29 & 14.93 & 1.93 \\
\hline $\mathrm{HX}-\mathrm{C}$ & 7.23 & 2.98 & 0.35 & 9.86 & 0.28 & 0.07 & 6.95 & 2.91 \\
\hline $\mathrm{HX}-\mathrm{CH} 4$ & - & - & 0.10 & 0.02 & - & - & - & - \\
\hline COMP & - & - & 0.35 & 0.40 & - & - & - & - \\
\hline PUMP & - & - & 0.004 & 0.006 & - & - & - & - \\
\hline
\end{tabular}

- the unavoidable exogenous part of the exergy destruction $\left(\dot{E}_{D, k}^{U N, E X}\right)$ that cannot be reduced because of technical limitations in the remaining components of the overall system for the given structure,

- the avoidable endogenous part of the exergy destruction ( $\dot{E}_{D, k}^{A V, E N}$ ), which can be reduced by improving the efficiency of the $k^{\text {th }}$ component, and finally

- the avoidable exogenous part of the exergy destruction ( $\dot{E}_{D, k}^{A V, E X}$ ) that can be reduced by improving the efficiency of the remaining components and of course by improving the efficiency in the $k^{\text {th }}$ component.

The methodology for splitting the exergy destruction into the above mentioned parts has been discussed in detail in the following publications: Tsatsaronis and Morosuk (2008a; 2008b; 2010) and Morosuk and Tsatsaronis (2009). The values of the four above mentioned parts of the exergy destruction within components of the SMR system are given in Table 4. The value of $\left(\frac{\dot{E}_{D, k}}{\dot{E}_{P, k}}\right)^{U N}$ for each component is given in Table 3 .

For the compressor, pump, HX-A, HX-CH4 and hydrogen separator, the concept of splitting the exergy destruction into endogenous/exogenous parts is not applied because of the following:

- Small values of the total and the avoidable part of the exergy destruction within compressor, pump and HXCH4 demonstrate that the SMR system cannot be significantly improved through decreasing irreversibilities within these three components.

- HX-A does not exist when the SMR system is simulated at theoretical operation conditions.

- The hydrogen separator is simulated as a "black box" according to information obtained from Simpson and Lutz, 2007. At least three processes take place within this component (Fig. 1). In this way, the exergy destruction should be split into the endogenous/ exogenous parts for each sub-component of the hydrogen separator.

\section{Results and discussions}

For all components (with the exception of HX-SHIFT) we have $\dot{E}_{D, k}^{E N}>\dot{E}_{D, k}^{E X}$, which shows that the interconnections among the components of the SMR system are not very strong. In addition, we have $\dot{E}_{D, k}^{U N}>\dot{E}_{D, k}^{A V}$ for COMPRET, REFORM, HT-SHIFT and LT-SHIFT. The potential for improving HT-SHIFT and LT-SHIFT is rather small also because the irreversibilities within these components are mainly caused by chemical reactions. The potential for improving COMBRET and REFORM is relative low ( $\dot{E}_{D, k}^{U N} \gg \dot{E}_{D, k}^{A V}$ for these components) but absolute values of $\dot{E}_{D, C O M B R E T}^{A V}$ and $\dot{E}_{D, R E F O R M}^{A V}$ are high and improving these components can significantly affect the results for the overall SMR process. For heat exchangers on the other side we obtain $\dot{E}_{D, k}^{U N}<\dot{E}_{D, k}^{A V}$. These components can be improved by decreasing the temperature difference within them.

The values of $\dot{E}_{D, k}^{A V, E N}$ indicate that the largest potential for improvement is realistically associated with the heat exchangers HX-B and HX-C. The design of these heat exchangers should be examined to identify opportunities for reducing the temperature differences (mainly) within these components. Among the chemical reactors only COMBRET and REFORM have large avoidable values. The exergy destruction in the heat exchanger between the two SHIFT reactors (HX-SHIFT) can be reduced mainly by improving the efficiency of the remaining components.

\section{Conclusions}

In this study an SRM process has been analyzed by means of an advanced exergetic method for chemical process. This analysis is based on previous methods applied to thermal systems, and is able to identify the endogenous/exogenous and unavoidable/avoidable parts of exergy destruction within each component pointing out the components with the highest improvement potentials.

When chemical reactions are present in an energy conversion process, the definition of the best operating conditions should take into account not only the most favorable thermodynamic conditions to drive the chemical reaction (such as temperature, pressure or reactant concentrations) but also possible catalyst deactivation, coke deposition and other factors that decrease the total conversion and consequently the exergetic efficiency of this type of components.

The data provided by the advanced exergetic analysis will be used in advanced exergoeconomic and exergoenvironmental analyses, in order to determine the avoidable costs and environmental impacts and the best 
way to improve the overall SMR system performance from the economic and ecological viewpoints.

\section{Acknowledgement}

The authors wish to thank the European Union for the financial support within the Framework of the INSPIRE Network (MRTN CT-2005-019296 - INSPIRE). A. Boyano is indebted to TU-Berlin and the Institute for Energy Engineering for her post-doctoral position.

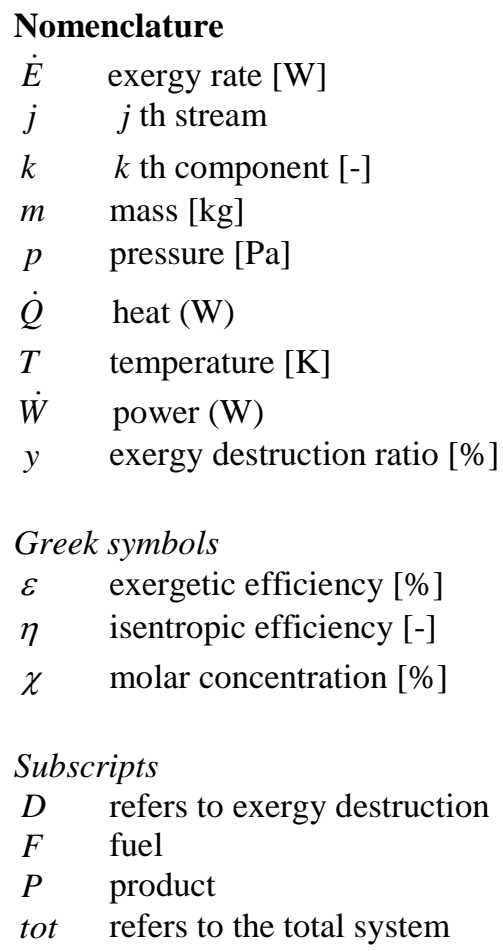

\section{Superscripts \\ $A V$ avoidable \\ $\mathrm{CH}$ chemical exergy \\ $E N$ endogenous \\ $E X$ exogenous \\ $\mathrm{PH}$ physical exergy \\ $U N$ unavoidable}

\section{Supercripts}

$\mathrm{CO}$ refers to $\mathrm{CO}$ mass fraction in a mixture

$\mathrm{CO}_{2}$ refers to $\mathrm{CO}_{2}$ mass fraction in a mixture

$\mathrm{CH}_{4}$ refers to $\mathrm{CH}_{4}$ mass fraction in a mixture

$\mathrm{CH}$ chemical

$\mathrm{H}_{2} \mathrm{O}$ refers to $\mathrm{H}_{2} \mathrm{O}$ mass fraction in a mixture

$\mathrm{H}_{2}$ refers to $\mathrm{H}_{2}$ mass fraction in a mixture

$H$ hybrid conditions

$P H \quad$ physical

$R \quad$ real conditions

$T$ theoretical conditions

\section{Subscripts}

$D$ exergy destruction

$F \quad$ exergy of fuel

$j \quad j$ th stream

$k \quad k$ th component

$P \quad$ exergy of product

0 reference state
Abbreviations

COMBRET combustion chamber using retenate stream and methane as fuel

COMP compressor

HT-SHIFT high-temperature water-gas-shift reactor

HX heat exchanger

H2-SEP hydrogen separation unit

LT-SHIFT low-temperature water-gas-shift reactor

MIXER mixer

PUMP pump

RAHX reversible adiabatic heat exchanger

REFORM reformer

SEP separator

SMR steam methane reforming

TV throttling valve

References

Aspen Plus, 2007, User Guide- Vol. 1 and 2-Release x.

Bejan A., Tsatsaronis G., Moran M., 1996, Thermal design and optimization, John Wiley and Sons, USA.

Boyano A., Blanco-Marigorta A.M., Morosuk T., Tsatsaronis G., 2011, Exergoenvironmental analysis of a steam methane reforming process for hydrogen production. Energy - The International Journal, Vol.36 (4), pp. 2202-2214.

Boyano A., Morosuk T., Blanco-Marigorta A.M., Tsatsaronis G., 2012, Conventional and advanced exergoenvironmental analysis of a steam methane reforming reactor for hydrogen production, International Journal of Cleaner Production, Vol. 20, pp. 152-160.

Cziesla F., Tsatsaronis G., Gao Z., 2006, Avoidable thermodynamic inefficiencies and costs in an externally fired combined cycle power plant, Energy Int. J., Vol. 31, Nos.10-11, pp. 1472-1489.

Lazzaretto A., Tsatsaronis G., 2006, SPECO: A systematic and general methodology for calculating efficiencies and costs in thermal systems, Energy - The International Journal, Vol. 31, pp. 1257-1289.

Morosuk T., Tsatsaronis G., 2009, Advanced Exergy Analysis for Chemically Reacting Systems Application to a Simple Open Gas-Turbine System, Int. J. of Thermodynamics, Vol. 12, No. 3, pp. 105-111.

Rosen M.A., 1991, Thermodynamic investigation of hydrogen production by steam-methane reformation. Int $J$ Hydrogen Energy, Vol. 16, No.3, pp. 207-217.

Simpson A.P., Lutz A.E., 2007, Exergy analysis of hydrogen production via steam methane reforming, Int. J. Hydrogen Energy, Vol. 32, pp. 4811-4820.

Tsatsaronis G., Cziesla F., 2002, Thermoeconomics. In: Enclyclopedia of Physical Science and Technology, $3^{\text {rd }}$ ed. Academic Press, Vol. 16, pp. 659-680.

Tsatsaronis G., Morosuk T., 2008, A general exergy-based method for combining a cost analysis with an environmental impact analysis. Part I. Proceedings of the ASME International Mechanical Engineering Congress and Exposition, Boston, USA, 2008, files IMECE2008-67218. 
Tsatsaronis G., Morosuk T., 2008, A general exergy-based method for combining a cost analysis with an environmental impact analysis. Part II. Proceedings of the ASME International Mechanical Engineering Congress and Exposition, Boston, USA, 2008, files IMECE2008-67219.

Tsatsaronis G., Morosuk T., 2010, Advanced exergetic analysis of a novel system for generating electricity and vaporizing liquefied natural gas. Energy - The international Journal, Vol. 35, pp. 820-829.
Tsatsaronis G., Park M.H., 2002, On avoidable and unavoidable exergy destructions and investment costs in thermal systems, Energy Conversion and Management, Vol. 43, pp.1259-1270.

Twigg M.V., ed., 1989, Catalyst handbook, $2^{\text {nd }}$ Edition, Wolfe Publishing Ltd.

Yang Y.C., Lee B.J., Chun Y.N., 2009, Characteristics of methane reforming using gliding arc reactor Energy The International Journal, Vol. 34, pp. 172-177. 